\title{
Alpha Thalassemia Changes Erythrocyte Heterogeneity in Sickle Cell Disease
}

\author{
Constance Tom Noguchi, George J. Dover, Griffin P. Rodgers, Graham R. Serjeant, Stylianos E. Antonarakis, \\ Nicholas P. Anagnou, Douglas R. Higgs, David J. Weatherall, and Alan N. Schechter \\ Laboratory of Chemical Biology, National Institute of Arthritis, Diabetes and Digestive and Kidney Diseases, and Clinical Hematology \\ Branch, National Heart, Lung and Blood Institute, National Institutes of Health, Bethesda, Maryland, 20205; Departments of Medicine \\ and Pediatrics, the Johns Hopkins University School of Medicine, Baltimore, Maryland 21205; Medical Research Council Laboratories, \\ University of the West Indies, Mona, Kingston, Jamaica; Medical Research Council, Molecular Haematology Unit, Nuffield Department \\ of Clinical Medicine, John Radcliffe Hospital, University of Oxford, England
}

\begin{abstract}
Homozygous $\alpha$-thalassemia has the beneficial effect in sickle cell anemia of reducing the hemolytic severity while changing several other hematological parameters. We examined in detail the cellular basis of some of these hematologic alterations. We find that the broad distribution in erythrocyte density and the large proportion of dense cells associated with sickle cell anemia are both reduced with coexisting $\alpha$-thalassemia. Measurements of glycosylated hemoglobin levels as a function of cell density indicate that the accelerated increase in cell density, beyond normal cell aging, in sickle cell anemia is also reduced with $\alpha$-thalassemia. The patients with homozygous $\alpha$-thalassemia and sickle cell disease have slightly lower levels of hemoglobin $F$ than the nonthalassemic sickle cell patients. Examination of hemoglobin $F$ production revealed that the proportion of hemoglobin $F$ containing reticulocytes remained unchanged, as did the proportion of hemoglobin $F$ in cells containing hemoglobin F (F cells). Preferential survival of $F$ cells occurs in sickle cell anemia, with or without $\alpha$-thalassemia, and the slight difference in hemoglobin $F$ levels appear to reflect differences in numbers of circulating $F$ cells. Thus, in sickle cell disease with coexisting $\alpha$-thalassemia, the change in the erythrocyte density profile, possibly due to inhibition of polymerization-related increases in cell density, explains the hematological improvement.
\end{abstract}

\section{Introduction}

The low solubility of deoxyhemoglobin S leading to polymerization at intracellular concentrations is the primary defect resulting in the pathophysiology of sickle cell disease (1). Corpuscular hemoglobin concentration $(\mathrm{CHC})^{1}(2,3)$ and corpuscular hemoglobin composition $(4,5)$ are the principal factors which determine the extent of intracellular polymerization. Several studies on sickle cell disease have detailed the tremendous heterogeneity in these parameters such as reflected

Address reprint requests to Dr. Noguchi, Building 10, Room 9N-307, National Institutes of Health, Bethesda, MD 20205.

Received for publication 25 June 1984 and in revised form 16 October 1984

1. Abbreviations used in this paper: $\mathrm{CHC}$, corpuscular hemoglobin concentration; D50, median cell density; $\mathrm{MCH}$, mean corpuscular hemoglobin; MCHC, mean corpuscular hemoglobin concentration; $\mathrm{R} 60,60 \%$ density range.

The Journal of Clinical Investigation, Inc.

Volume 75, May 1985, 1632-1637 in the heterogeneous density distribution (6-9), in hemoglobin $F$ levels (10-12) and in hemoglobin F-containing cells (1314). While chemical and biophysical processes associated with polymerization of hemoglobin $S$ have been extensively studied (15), the precise relationship between polymer formation and disease manifestation is unknown. However, recent studies have shown that the degree of anemia in twelve sickle syndromes can be largely accounted for by differences in intracellular polymer content due to variation in hemoglobin composition and concentration (16).

Recent reports by Embury et al. (17) and Higgs et al. (18) demonstrated the beneficial effects of $\alpha$-thalassemia, particularly homozygous $\alpha$-thalassemia $(\alpha-/ \alpha-)$, on sickle cell disease with respect to the hemolytic rate and associated changes in other hematological parameters. For example, hemoglobin levels were found to be $\sim 1 \mathrm{~g} / \mathrm{dl}$ higher in sickle cell patients with coexisting homozygous $\alpha$-thalassemia than those without $\alpha$-thalassemia (18). The coexistence of $\alpha$-thalassemia with sickle cell disease resulted in decreased mean corpuscular volume, mean corpuscular hemoglobin $(\mathbf{M C H})$, and mean corpuscular hemoglobin concentration (MCHC) (17-20). In addition, Embury et al. found an increased level of hemoglobin $F$ in sickle cell patients with $\alpha$-thalassemia (17). However, the much larger patient population studied by Higgs et al. exhibited a slight decrease in the level of hemoglobin $F$ in the presence of $\alpha$-thalassemia (18). Since corpuscular hemoglobin composition and $\mathrm{CHC}$ both affect polymer formation, we have examined in detail the variation in these hematological parameters. We have considered specifically the detailed distribution of $\mathrm{CHC}$, the production and distribution of cells which contain hemoglobin $F$ ( $F$ cells), and cell age in sickle cell anemia with and without $\alpha$-thalassemia.

\section{Methods}

For this study, 42 patients were selected at random from the clinic for sickle cell disease at the University Hospital of the West Indies (Kingston, Jamaica) without knowledge of hemoglobin $F$ levels, but for which the number of $\alpha$-globin genes was previously determined (these patients are a subset of those included in the study reported in reference 18). 10 consecutive sickle cell patients from the Clinical Hematology Service from the National Institutes of Health were also selected. When possible, individuals with two and four $\alpha$-globin genes were age- and sex-matched.

Blood samples were obtained from individuals who were not in crisis or recovering from crisis at the time. Diagnosis of sickle cell anemia was made on the basis of electrophoresis and family studies when possible. The diagnosis of heterozygous $(\alpha-/ \alpha \alpha)$ or homozygous $(\alpha-/ \alpha-) \alpha$-thalassemia was made on the basis of restriction endonuclease analysis of DNA obtained from peripheral blood leukocytes cells. Probes from either the $\alpha$-globin-specific plasmid JW101 (21) or the 
$\alpha$-globin subclone pRB $\alpha 1$ (22) were used for $\alpha$-globin gene mapping $(23,24)$.

Phthalate esters were prepared by mixing dimethyl phthalate (sp. gr. 1.189, Fisher Scientific Co., Pittsburgh, PA) and $N$-butyl phthalate (sp. gr. 1.042, Fisher Scientific Co.) to obtain densities ranging from 1.060 to 1.136 following the procedure of Danon and Marikovsky (25). Microcapillary tubes were loaded with the phthalate esters and filled with whole blood, the ester end was sealed with clay, and the tube was spun in a microhematocrit centrifuge for $7 \mathrm{~min}$ at $25^{\circ} \mathrm{C}$. The microhematocrit centrifuge was reequilibrated to $25^{\circ} \mathrm{C}$ between spins. The fraction of packed erythrocytes under each phthalate mixture was measured.

Discontinuous Stractan gradients were prepared by the method of Corash et al. (26) as modified by Clark et al. (27). Cells were washed three times and resuspended in buffer and layered onto the gradient (the osmolality of the Stractan and buffer were adjusted to 290 mosmol/liter, $\mathrm{pH}$ 7.4). The Stractan gradient made up of layers of 19 , $21,22,23,24,26,28$, and $33 \%$ was spun in a SW28.1 rotor (Beckman Instruments, Fullerton, CA) at $20,000 \mathrm{rpm}$ for $45 \mathrm{~min}$ at $5^{\circ} \mathrm{C}$. The eight fractions of cells were collected by using a tube slicer (TUBS200 , Nuclear Supply Service, Washington, DC) with $>95 \%$ recovery of cells. For glycosylated hemoglobin determinations, the cells were washed in phosphate-buffered saline, $\mathrm{pH}$ 7.4. The level of glycosylation was determined by affinity chromatography using a column of immobilized $m$-aminophenylboronic acid on agarose beads (GLYCO-GEL; Pierce Chemicals Co., Rockford, IL) (28).

Reticulocytes and erythrocytes containing hemoglobin $F$ ( $F$ retics and $F$ cells, respectively) were enumerated by a microscopic immunoprecipitate assay using rabbit anti-human hemoglobin $F$ antibody (29). The amount of hemoglobin $F$ in individual reticulocytes and erythrocytes was determined by microdensitometric analysis of immunoprecipitate reactions $(30)$.

\section{Results}

We analyzed 19 individuals with sickle cell anemia and homozygous $\alpha$-thalassemia ( $\alpha-/ \alpha-), 13$ individuals with sickle cell anemia and heterozygous $\alpha$-thalassemia $(\alpha-/ \alpha \alpha)$, and 20 individuals with sickle cell disease but without $\alpha$-thalassemia $(\alpha \alpha / \alpha \alpha)$. The average density profile obtained from the phthalate ester technique for individuals with sickle cell disease is illustrated in Fig. 1. "Fraction-under" values represent the proportion of packed cell volume that spun through the phthalate ester interface, i.e., the proportion of cells with density greater than the phthalate ester mixture. (The actual density distribution can be obtained by taking the first derivative of this density profile, the difference between the "fraction under" for adjacent capillaries, and is also shown in Fig. 1.) We characterize these density profiles using three parameters. The median cell density, referred to as D50 (specific gravity units), represents the density which separates the cell population such that $50 \%$ of the packed cell volume is above and $50 \%$ is below this density of phthalate ester. The dense fraction is described by the proportion of cells $>1.12$, i.e., with a $\mathrm{CHC}$ $>37 \mathrm{~g} / \mathrm{dl}$. For normal individuals, no cells are found in the "fraction under" for phthalate ester densities $>1.12$ (unpublished data). As an indication of the spread in density distribution, we define the R60 (specific gravity units) which is the density range minus the $20 \%$ lightest cells and the $20 \%$ densest cells. This parameter has been selected in order to minimize the influence of increased reticulocytosis or of increased dense cells on the transition range. Specifically, the R60 represents the middle density range in which $60 \%$ of the cells can be found.
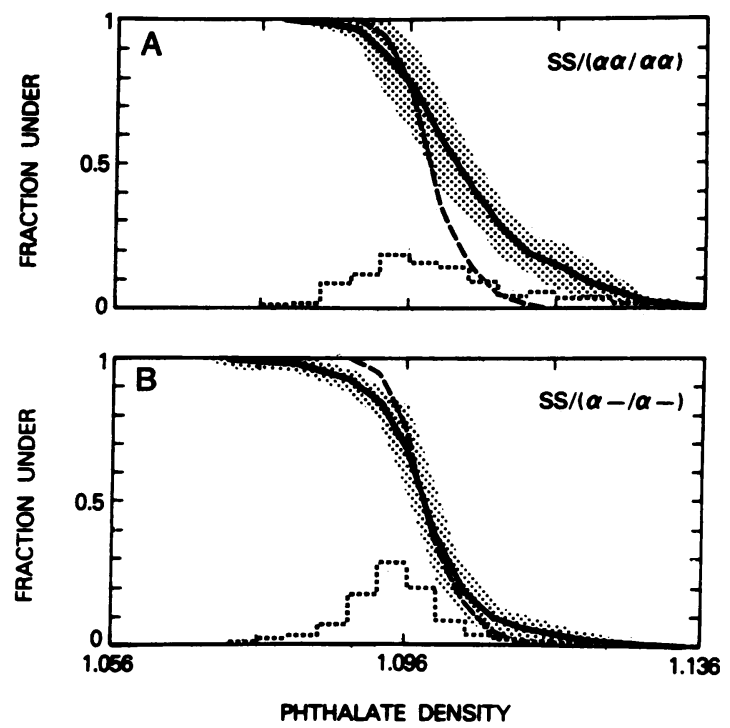

Figure 1. The mean density profile for individuals with sickle cell anemia expressed as a cumulative frequency, i.e., the proportion of packed cells or "fraction under" the respective density of phthalate ester. $(A)$ represents those individuals without $\alpha$-thalassemia $(\mathrm{SS} /(\alpha \alpha)$ $\alpha \alpha)$ and $(B)$ represents those individuals with homozygous $\alpha$-thalassemia $(\mathrm{SS} /(\alpha-/ \alpha-))$. The dotted area represents $1 \mathrm{SD}$. The profile for normal individuals is indicated by the long dashed line. The short dashed line represents the histogram for the density distribution (the first derivative of the phthalate ester profile). The D50, R60, and dense cell $>1.12$ fraction for normal individuals are $1.099 \pm 0.002$, $0.007 \pm 0.001$, and $0.001 \pm 0.002$, respectively (Rodgers, G. P., and C. T. Noguchi; unpublished observation).

Fig. $1 B$ illustrates the erythrocyte density profiles obtained for individuals with sickle cell disease and homozygous $\alpha$-thalassemia $(\alpha-/ \alpha-)$. The entire distribution is shifted to lower density values, with a narrower transition, i.e., the R60 value is lower. The dense cell fraction $(>1.12$ or $>37 \mathrm{~g} / \mathrm{dl})$ is also greatly reduced. The MCHC is $35.9 \pm 2.9 \mathrm{~g} / \mathrm{dl}$ for $(\alpha \alpha / \alpha \alpha)$ individuals compared with $31.4 \pm 1.7$ for $(\alpha-/ \alpha-)$ individuals. These MCHC values are not significantly different from those reported by Higgs et al. (18). (The greater difference between the $(\alpha-/ \alpha-)$ and $(\alpha \alpha / \alpha \alpha)$ genotypes reported here may be attributed to the smaller sample size of this study.)

Fig. 2 illustrates our detailed analysis of the density profile obtained for the individuals with sickle cell anemia and with

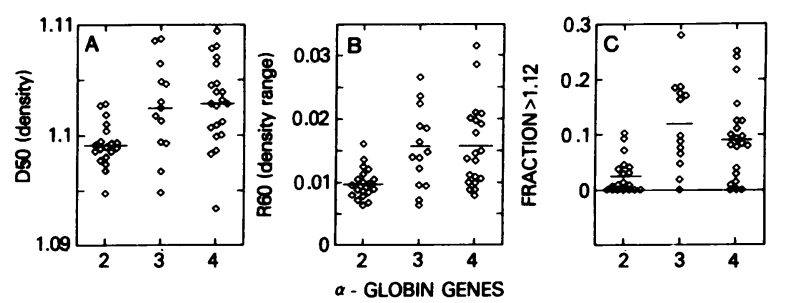

Figure 2. The mean cell density of D50 $(A)$, the R60 $(B)$, and the dense cell fraction $>1.12$ or $>37 \mathrm{~g} / \mathrm{dl}(C)$ for individuals with sickle cell anemia with homozygous $\alpha$-thalassemia $((\alpha-/ \alpha-)$ or two $\alpha$-globin genes), with heterozygous $\alpha$-thalassemia $((\alpha-/ \alpha \alpha)$ or three $\alpha$-globin genes) and without $\alpha$-thalassemia $((\alpha-/ \alpha-)$ or four $\alpha$-globin genes). The solid lines indicate the mean value for each set of data. 
homozygous $\alpha$-thalassemia ( $\alpha-/ \alpha-)$, individuals with sickle cell anemia and heterozygous $\alpha$-thâlassemia $(\alpha-/ \alpha \alpha)$ and individuals with sickle cell anemia but without $\alpha$-thalassemia $(\alpha \alpha / \alpha \alpha)$. The median density or D50 for the $(\alpha-/ \alpha-)$ genotype has an average value $( \pm S D)$ of $1.099 \pm 0.002$ compared with $1.102 \pm 0.003$ for the $(\alpha-/ \alpha \alpha)$ genotype and $1.103 \pm 0.004$ for the $(\alpha \alpha / \alpha \alpha)$ genotype individuals. The reduction in D50 in the homozygous $\alpha$-thalassemia individuals is representative of the overall shift of the erythrocytes to lighter densities or smaller CHC values. The analysis for the density range (R60) is illustrated in Fig. $2 B$. The R60 for $(\alpha-/ \alpha-)$ is $(10 \pm 2)$ $\times 10^{-3}$ compared with $(16 \pm 7) \times 10^{-3}$ for $(\alpha-/ \alpha \alpha)$ and $(17 \pm 7)$ $\times 10^{-3}$ for $(\alpha \alpha / \alpha \alpha)$ genotype individuals. $(\alpha-/ \alpha \alpha)$ and $(\alpha \alpha /$ $\alpha \alpha)$ genotype sickle cell patients represent a broader density distribution by a factor of $\sim 1.6$ compared with the $(\alpha-/ \alpha-)$ genotype. As an indication of the proportion of dense cells, we use the percentage of packed cells $>1.12$ (Fig. $2 C$ ). The percentage of dense cells is $2 \pm 2 \%$ for $(\alpha-/ \alpha-)$ compared with $12 \pm 8 \%$ for $(\alpha-/ \alpha \alpha)$ and $8 \pm 8 \%$ for $(\alpha \alpha / \alpha \alpha)$ genotypes. In summary, for individuals with sickle cell anemia and homozygous $\alpha$-thalassemia $(\alpha-/ \alpha-)$, the density profile is shifted to lower values (for D50, $P<.01$ ), is distributed over a narrower density range (for $\mathrm{R} 60, P<.001$ ), and is reduced in the proportion of dense cells (for fraction $>1.12, P<.005$ ) compared with the profiles for the $(\alpha \alpha / \alpha \alpha)$ genotype individuals. The $(\alpha-/ \alpha \alpha)$ genotype density profiles were not found to be significantly different from the $(\alpha \alpha / \alpha \alpha)$ genotype density profiles.

To examine the relationship between cell age and cell density, we fractionated the whole blood samples on discontinuous Stractan gradients and measured the level of glycosylated hemoglobin. Since intracellular glycosylation of hemoglobin is a slow, irreversible, and nonenzymatic process, the level of glycosylated hemoglobin accumulated during the lifespan of the erythrocyte can be used as an index of cell age $(31,32)$. The level of glycosylated hemoglobin for individuals with sickle cell anemia in the absence of $\alpha$-thalassemia is illustrated in Fig. 3 (solid line). The Stractan fractions are represented in increasing order of density. The maximal level of glycosylated hemoglobin is found in the middle fractions, particularly fraction 6, indicating that the denser cell fractions (fraction 7 and 8) do not coincide with the oldest cells. In contrast, in the $\left(\alpha-/ \alpha^{-}\right)$genotype population (shown as the dashed line, Fig. $3)$, there is no significant reduction in the level of glycosylated

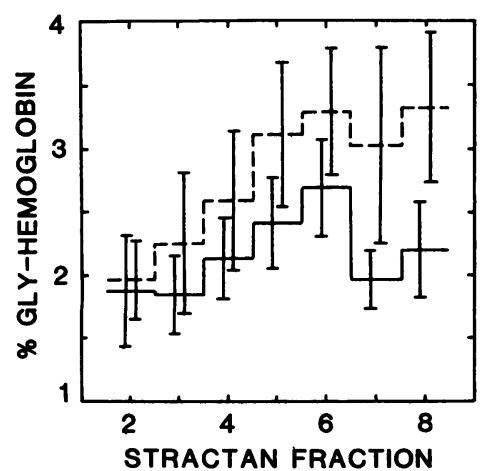

Figure 3. The level of glycosylated hemoglobin (\% gly-hemoglobin) as a function of erythrocyte density. The density is indicated by Stractan fraction number which increases with increasing fraction number (see text for Stractan gradient details). The solid line represents mean values for individuals with sickle cell anemia without $\alpha$-thalassemia $((\alpha \alpha / \alpha \alpha)$ genotype) and the dashed line represents mean values for individuals with sickle cell anemia and homozygous $\alpha$-thalassemia $(\alpha-/ \alpha-)$ genotype. The error bars indicate 1 SD. hemoglobin in fractions 7 and 8 . It is readily apparent that the overall levels of glycosylated hemoglobin for the $(\alpha-/ \alpha-)$ genotype individuals is greater than the $(\alpha \alpha / \alpha \alpha)$ genotype individuals, consistent with the greater cell survival in individuals with sickle cell disease and $\alpha$-thalassemia recently reported by de Ceulaer et al. (33).

The hemoglobin $F$ level of the individuals with the $(\alpha \alpha)$ $\alpha \alpha)$ genotype was $5.6 \pm 3.8 \%$ while that of the $(\alpha-/ \alpha-)$ genotype was $5.1 \pm 3.5 \%$. The production of hemoglobin $F$ is determined by the number of hemoglobin $F$ containing reticulocytes ( $F$ retics), the amount of hemoglobin $F$ in hemoglobin $F$-containing erythrocytes ( $F$ cells), and the relative survival of $F$ cells to non-F-cells. We examined these three parameters in sickle cell anemia with and without $\alpha$-thalassemia. In the two groups of sickle cell anemia with $(\alpha-/ \alpha-)$ and $(\alpha \alpha / \alpha \alpha)$ genotypes, we find that the percentage of reticulocytes containing hemoglobin $F$ is not different (percentage of $F$ retics is $18 \pm 7 \%$ with $\alpha$-thalassemia $(\alpha-/ \alpha-)$ and $18 \pm 11 \%$ in the absence of $\alpha$ thalassemia) (Fig. $4 A$ ). The MCH for the $(\alpha-/ \alpha-)$ and $(\alpha \alpha /$ $\alpha \alpha)$ genotypes are $23.8 \pm 2.1$ and $30.2 \pm 3.1 \mathrm{pg}$, respectively. The reduction in $\mathrm{MCH}$ in the presence of $\alpha$-thalassemia is significant $(P<0.001)$. Amounts of hemoglobin $F$ in $F$ cells are reduced proportionately with the reduction in $\mathrm{MCH}(P$ $<0.02$ ), with $4.2 \pm 0.7 \mathrm{pg} \mathrm{HbF} / \mathrm{F}$ cell in the presence of homozygous $\alpha$-thalassemia compared with $5.6 \pm 1.3 \mathrm{pg} \mathrm{HbF/F}$ cell in sickle cell anemia alone (Fig. $4 \mathrm{~B}$ ). The percentage of $F$ cells is $28.3 \pm 17.6 \%$ for the $(\alpha-/ \alpha-)$ and $33.5 \pm 20.5 \%$ for the $(\alpha \alpha / \alpha \alpha)$ genotypes. Although the differences between these latter values are not statistically significant $(P=0.27)$, a trend toward lower percentages of $F$ cells for the $(\alpha-/ \alpha-)$ genotype is suggested.

The relationship between cell density and proportion of $F$ cells provides additional evidence that the mechanism responsible for the premature increase in cell density found in sickle cell anemia is related to polymer formation. Cells fractionated on discontinuous Stractan density gradients were analyzed for their hemoglobin $F$ content. The proportion of $F$ cells in each fraction is illustrated in Fig. 5. These results are normalized to the average value for the number of $F$ cells. Fraction 1 in which the majority of leukocytes are found is omitted because of high leukocyte count. For both $(\alpha-/ \alpha-)$ and $(\alpha \alpha / \alpha \alpha)$ genotypes, the proportion of $F$ cells initially increases with increasing density and then decreases for the most dense

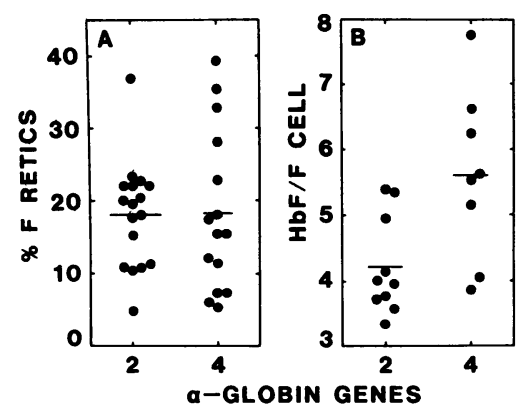

Figure 4. $(A)$ The percentage of hemoglobin F-containing reticulocytes $(F$ retic) and $(B)$ the amount of hemoglobin $F$ (picograms of $\mathrm{HbF}$ ) in hemoglobin F-containing erythrocytes ( $F$ cells) for individuals with sickle cell anemia with homozygous $\alpha$-thalassemia $((\alpha-/ \alpha-)$ or two $\alpha$-globin genes) and without $\alpha$-thalassemia $((\alpha \alpha / \alpha \alpha)$ or four $\alpha$-globin genes). The solid line indicates the mean value. 


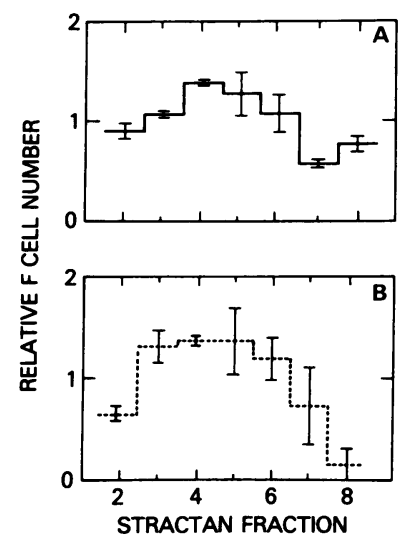

fractions. The fractions which contain the largest proportion of $F$ cells coincide with the older cells (see Fig. 3) and the majority of the most dense cells are non-F cells. These results are consistent with earlier reports of a reduced level of hemoglobin $\mathrm{F}$ in the densest cell fraction (34).

\section{Discussion}

In individuals with sickle cell anemia and the $(\alpha \alpha / \alpha \alpha)$ genotype, detailed examination of the $\mathrm{CHC}$ reveals a broad distribution with an unusually large proportion of cells with $\mathrm{CHC}$ values significantly greater than the MCHC (Fig. 1). Compared with normal individuals, the broader distribution results in a larger value for the $60 \%$ density transition (R60) and an increase in the proportion of dense cells which is all but absent in normal individuals $(35,36)$. Since these parameters are little influenced by the increased reticulocyte production, they presumably reflect an accelerated increase in cell density beyond normal cell aging (26) due to the cycles of intracellular polymerization $(8,9)$.

With the additional factor of $\alpha$-thalassemia, the erythrocyte density profiles for sickle cell patients change (Fig. $1 B$ ) so that they exhibit a lower median value (D50), a narrower density range (lower R60), and a much smaller proportion of dense cells $>37 \mathrm{~g} / \mathrm{dl}$ (Fig. 2), manifest clinically as an overall decrease in MCHC. In general, the density profile is shifted toward that for normal individuals as also illustrated by Embury et al. (36). These changes in the density distribution with an overall reduction of heterogeneity in cell density found in sickle cell anemia with homozygous $\alpha$-thalassemia $(\alpha-/ \alpha-)$ explain the lower value for MCHC reported by Embury et al. (17) and Higgs et al. (18) compared to sickle cell anemia alone with the $(\alpha \alpha / \alpha \alpha)$ genotype. The density profile for individuals with sickle cell anemia and heterozygous $\alpha$-thalassemia $(\alpha-/ \alpha \alpha)$ is not significantly different from individuals with sickle cell anemia alone $(\alpha \alpha / \alpha \alpha)$ (Fig. 2).

In normal individuals, erythrocyte density increases with cell age (26). In sickle cell anemia, erythrocyte survival time is decreased (34) but the increase in erythrocyte density is accelerated beyond that of normal cell aging, particularly for what appears to be a subpopulation destined to become dense cells. Fig. 3 illustrates that the dense cell population (fractions 7 and 8 separated on discontinuous Stractan gradients) in sickle cell anemia is indeed not the oldest subpopulation as measured by the level of glycosylated hemoglobin. This accelerated increase in cell density can be explained at least in part by the polymerization of hemoglobin $\mathrm{S}$ within the erythrocyte. Alternatively, the cell density profile also suggests the possibility that in sickle cell anemia erythrocytes emerge from the marrow as a more heterogeneous population. Other membrane-related phenomena may also be partly responsible for density changes, although specific binding of hemoglobin $\mathrm{S}$ to the membrane may be unlikely (37).

de Ceulaer et al. (33) have recently reported that in sickle cell anemia with $\alpha$-thalassemia $(\alpha-/ \alpha-)$, cell survival time is increased. This is also evident by the increased proportion of glycosylated hemoglobin as illustrated in Fig. 3. The decrease in cell age, as measured by the level of glycosylated hemoglobin in the most dense cell fractions ( 7 and 8 in Fig. 3), is less in the sickle cell patients with homozygous $\alpha$-thalassemia, suggesting that the accelerated increase in cell density in this disease is proportionately less when these two syndromes coexist.

The three parameters which determine the level of hemoglobin $F$ are the proportion of $F$ reticulocytes, the amount of hemoglobin $F$ per $F$ cell, and the survival of $F$ cells and nonF-cells (14). Embury et al. (17) proposed that the ameliorating effect of $\alpha$-thalassemia $(\alpha-/ \alpha-)$ on sickle cell anemia is partially due to an increase in the hemoglobin $F$ level, a finding not confirmed by Higgs et al. (18) nor true of the patient populations (in part overlapping with that of Higgs et al. [18]) reported in this study. We examined the parameters which determine hemoglobin $F$ and found the proportion of $F$ reticulocytes was unchanged with or without coexisting $\alpha$-thalassemia. The picogram amount of hemoglobin $F$ per $F$ cell was lower for sickle cell anemia with homozygous $\alpha$-thalassemia (Fig. $4 \mathrm{~B}$ ), but the percent of hemoglobin $\mathrm{F} / \mathrm{F}$ cell was the same since there was proportionate decrease in $\mathrm{MCH}$. That is, the proportions of hemoglobin $\mathrm{F}$ per $\mathrm{F}$ cell are similar with and without homozygous $\alpha$-thalassemia. Hence, differences in the levels of hemoglobin $F$ with or without coexisting $\alpha$-thalassemia would be reflected directly in differences in the total percentage of $F$ cells, which while not statistically significant, tend to be lower in those with homozygous $\alpha$-thalassemia.

Examination of the percentage of $F$ cells as a function of density (Fig. 5) indicates that the dense cell fractions contain proportionately fewer $\mathrm{F}$ cells. Hence, preferential removal of dense cells from the circulation would explain the selective survival of $F$ cells associated with sickle cell anemia and that the advantage of $\mathrm{F}$ cells should be slightly greater in $(\alpha \alpha / \alpha \alpha)$ individuals who have a greater proportion of dense cells than $(\alpha-/ \alpha-)$ individuals.

The hypothesis that accelerated increases in cell density in sickle cell anemia are a result of intracellular polymer formation implies that decreases in polymer formation would retard such changes. When hemoglobin $F$ is present, the potential for polymer formation is reduced compared with nonhemoglobin F-containing cells of the same CHC $(3,4)$. Our detailed examination of the distribution of $F$ cells with respect to cell density (Fig. 5) indicates that, in sickle cell anemia, the number of $F$ cells is reduced in the dense cell fractions (fractions 7 and 8 as separated on the discontinuous Stractan gradients). This supports the above hypothesis and suggests that the presence of hemoglobin $\mathrm{F}$ can modify but not eliminate the premature increase in cell density. (Note that the proportion of cells in fractions 7 and 8 is about ten times greater for the $(\alpha \alpha / \alpha \alpha)$ genotype than the $(\alpha-/ \alpha-)$ genotype.) 
Hemoglobin composition, hemoglobin concentration, and the erythrocyte density profile are important factors in determining polymer formation (2-5). However, the detailed mechanism by which polymer formation results in disease manifestation is unknown. We have shown that the potential for polymer formation based on the average hemoglobin composition and concentration for 12 different sickle syndromes explains to a large extent the degree of hemolytic anemia associated with each syndrome (16). To consider the disease manifestation within a population, the nature of erythrocyte heterogeneity for single individuals must be taken into account. However, the studies presented here indicate the complexities of cell heterogeneity and the difficulty in choosing a single parameter to describe it.

For sickle cell anemia with homozygous $\alpha$-thalassemia $(\alpha-/ \alpha-)$, we have demonstrated the manner in which changes in cell heterogeneity result in a decrease in $\mathrm{MCHC}$. The premature increase in cell density associated with sickle cell anemia is less marked in the presence of $\alpha$-thalassemia. The reduction in cell heterogeneity, and thus the potential for polymer formation, and the increase in hemoglobin level associated with the $(\alpha-/ \alpha-)$ genotype further illustrates the association between polymer formation and hemolytic severity. The beneficial effect of $\alpha$-thalassemia on clinical severity is questionable. The studies by Embury et al. (17) and Higgs et al. (18) suggests that clinical course may indeed be more mild. Recent rheologic studies of Serjeant et al. (38) and Embury et al. (36) demonstrated improved deformability of individual cells presumably due to decreased $\mathrm{CHC}$ and decreased polymer formation. However, this salutory effect may be offset by the increase in hemoglobin level (37). Recently, Steinberg et al. (39) have provided additional data questioning the clinical benefit of $\alpha$-thalassemia in sickle cell disease. Nevertheless, the presence of homozygous $\alpha$-thalassemia does result in improved hematological parameters and erythrocyte profiles in sickle cell anemia. Whatever the clinical benefits that $\alpha$-thalassemia confers on sickle cell anemia may be, the finding of striking changes in the cell density profiles is likely to be of relevance for understanding the role of erythrocyte heterogeneity in determining the severity of the sickle syndromes.

\section{Acknowledgments}

We thank Laura Barry for excellent secretarial help.

Dr. Rodgers is a Fellow of the Robert Wood Johnson Foundation; Dr. Antonarakis is the recipient of a New Investigator Research Award from the National Institutes of Health. Dr. Anagnou was supported by a grant from the Cooley's Anemia Foundation. Dr. Higgs and Dr. Weatherall thank The Rockefeller Foundation for financial support.

\section{References}

1. Bunn, H. F., B. G. Forget, and H. M. Ranney. 1977. Human hemoglobins. W. B. Saunders, Philadelphia. 228-281.

2. Hofrichter, J., P. D. Ross, and W. A. Eaton. 1974. Kinetics and mechanism of deoxyhemoglobin S gelation: a new approach to understanding sickle cell disease. Proc. Natl. Acad. Sci. USA. 71:4864-4868.

3. Noguchi, C. T., and A. N. Schechter. 1981. The intracellular polymerization of sickle hemoglobin and its relevance to sickle cell disease. Blood. 58:1057-1068.

4. Sunshine, H. R., J. Hofrichter, and W. A. Eaton. 1979. Gelation of sickle cell hemoglobin in mixtures with normal adult and fetal hemoglobin. J. Mol. Biol. 133:435-467.
5. Noguchi, C. T. 1984. Polymerization in erythrocytes containing $S$ and non-S hemoglobins. Biophys. J. 45:1153-1158.

6. Seakins, M., W. N. Gibbs, P. F. Milner, and J. F. Bertles. 1976. Erythrocyte $\mathrm{HbS}$ concentration. An important factor in the low oxygen affinity of blood in sickle cell anemia. J. Clin. Invest. 52:559-565.

7. Clark, M. R., N. Mohandas, and S. B. Shohet. 1980. Deformability of oxygenated irreversibly sickled cells. J. Clin. Invest. 65:189-196.

8. Fabry, M. E., and R. L. Nagel. 1982. The effect of deoxygenation of red cell density: significance for the pathophysiology of sickle cell anemia. Blood. 60:1370-1377.

9. Noguchi, C. T., D. A. Torchia, and A. N. Schechter. 1983. Intracellular polymerization of sickle hemoglobin. Effects of cell heterogeneity. J. Clin. Invest. 72:846-852.

10. Serjeant, G. R. 1975. Fetal hemoglobin in homozygous sickle cell disease. Clin. Haematol. 4:109-122.

11. Pembrey, M. E., W. G. Wood, D. J. Weatherall, and R. P. Perrine. 1978. Fetal haemoglobin production and the sickle gene in the oases of eastern Saudi Arabia. Br. J. Haematol. 40:415-429.

12. Powars, D. R., W. A. Schroeder, J. N. Weiss, L. S. Chan, and S. P. Azen. 1980. Lack of influence of fetal hemoglobin levels or erythrocyte indices on severity of sickle cell anemia. J. Clin. Invest. 65:732-740.

13. Dover, G. J., S. H. Boyer, S. Charache, and K. Heintzelman. 1978. Individual variation in the production and survival of $F$ cells in sickle cell disease. N. Engl. J. Med. 299:1428-1435.

14. Dover, G. J., S. H. Boyer, and M. E. Pembrey. 1981. F-cell production in sickle cell anemia: regulation by genes linked to $\beta$-hemoglobin locus. Science (Wash. DC). 211:1441-1444.

15. Dean, J., and A. N. Schechter. 1978. Sickle cell anemia: molecular and cellular basis of therapeutic approaches. N. Engl. J. Med. 299:752-763; 804-811; 863-870.

16. Brittenham, G. M., A. N. Schechter, and C. T. Noguchi. 1985. Hemoglobin $\mathrm{S}$ polymerization: primary determinant of the hemolytic and clinical severity of the sickling syndromes. Blood. 65:183-189.

17. Embury, S. H., A. M. Dozy, J. Miller, J. R. Davis, Jr., K. M. Kleman, H. Presiler, E. Vichinsky, W. N. Lande, B. H. Lubin, Y. W. Kan, and W. C. Mentzer. 1982. Concurrent sickle cell anemia and $\alpha$-thalassemia: effect on severity of anemia. N. Engl. J. Med. 306:270274.

18. Higgs, D. R., B. E. Aldridge, J. Lamb, J. B. Clegg, D. J. Weatherall, R. J. Hayes, Y. Grandison, Y. Lowrie, K. P. Mason, B. E. Serjeant, and G. R. Serjeant. 1982. The interaction of alphathalassemia and homozygous sickle cell disease. N. Engl. J. Med. 306: 1441-1446.

19. Weatherall, D. J., J. B. Clegg, J. Blankson, and J. R. McNeil. 1969. A new sickling disorder resulting from interaction of the genes for haemoglobin S and $\alpha$-thalassemia. Br. J. Haematol. 17:517-526.

20. Weatherall, D. J., and J. B. Clegg. 1981. The Thalassemia Syndromes. Blackwell Publisher, Oxford. 613-644.

21. Wilson, J. T., L. B. Wilson, J. K. deRiel, L. Villa-Komaroff, A. Efstratiadis, B. G. Forget, and S. M. Weissman. 1978. Insertion of synthetic copies of human globin genes into bacterial plasmids. Nucleic Acids Res. 5:563-581.

22. Higgs, D. R., L. Pressley, G. R. Serjeant, J. B. Clegg, and D. J. Weatherall. 1981. The genetics and molecular basis of alpha thalassemia in association with $\mathrm{HbS}$ in Jamaican Negroes. Br. J. Haematol. 47:43-56.

23. Lauer, J., J. S. Cherkun, and T. Maniatis. 1980. The chromosomal arrangement of human $\alpha$-like globin genes: sequence homology and $\alpha$-globin gene deletions. Cell. 20:119-130.

24. Antonarakis, S. E., J. A. Phillips, and H. H. Kazazian. 1982. Genetics diseases: diagnosis by restriction endonuclease analysis. $J$. Pediatr. 100:845-856.

25. Danon, D., and Y. Marikovsky. 1964. Determination of density distribution of red cell population. J. Lab. Clin. Med. 64:668-674.

26. Corash, L. M., S. Piomelli, H. C. Chen, C. Seaman, and E. 
Gross. 1974. Separation of erythrocytes according to age on a simplified density gradient. J. Lab. Clin. Med. 84:147-151.

27. Clark, M. R., A. C. Greenquist, and S. B. Shohet. 1976. Stabilization of the shape of sickled cells by calcium and A23187. Blood. 48:899-909.

28. Mallia, A. K., G. T. Hermanson, R. I. Krohn, E. K. Fujimoto, and P. K. Smith. 1981. Preparation and use of a boronic acid affinity support for separation and quantitation of glycosylated hemoglobins. Anal. Lett. 14(B8):649-661.

29. Dover, G. J., S. H. Boyer, and W. R. Bell. 1978. Microscopic method for assaying $\mathrm{F}$ cell production: illustrative changes during infancy and in aplastic anemia. Blood. 52:646-672.

30. Dover, G. J., and S. H. Boyer. 1980. Quantitation of hemoglobins within individual red cells: asynchronous biosynthesis of fetal and adult hemoglobin during erythroid maturation in normal subjects. Blood. 56:1082-1091.

31. Bunn, H. F., D. N. Haney, S. Kamin, K. H. Gabbay, and P. M. Gallop. 1976. Biosynthesis of hemoglobin $A_{\mathrm{lc}}$ : slow glycosylation of hemoglobin in vivo. J. Clin. Invest. 57:1652-1659.

32. Fitzgibbons, J. F., R. D. Koler, and R. T. Jones. 1976. Red cell age-related changes of hemoglobins $A_{l a+b}$ and $A_{l c}$ in normal and diabetic subjects. J. Clin. Invest. 58:820-824.

33. deCeulaer, K., D. R. Higgs, D. J. Weatherall, R. J. Hayes, B. E. Serjeant, and G. R. Serjeant. 1983. $\alpha$-Thalassemia reduces the hemolytic rate in homozygous sickle cell disease. N. Engl. J. Med. 309:189-190.

34. Bertles, J. F., and P. F. A. Milner. 1968. Irreversibly sickled erythrocytes: a consequence of the heterogeneous distribution of hemoglobin types in sickle cell anemia. J. Clin. Invest. 47:1731-1740.

35. Oda, S. E., E. Oda, and K. R. Tanaka. 1978. Relationship of density distribution and pyruvate kinase electrophoretic pattern of erythrocytes in sickle cell disease and other disorders. Acta Haematol. 60:201-209.

36. Embury, S. H., M. R. Clark, G. Monroy, N. Mohandas, and R. Hoesch. 1984. Concurrent sickle cell anemia and $\alpha$-thalassemia. $J$. Clin. Invest. 74:116-123.

37. Eisinger, J., J. Flores, and R. M. Bookchin. 1984. The cytosolmembrane interface of normal and sickle erythrocytes. J. Biol. Chem. 259:7169-7177.

38. Serjeant, B. E., K. P. Mason, M. W. Kenny, J. Stuart, D. R. Higgs, D. J. Weatherall, R. J. Hayes, and G. R. Serjeant. 1983. Effect of alpha thalassemia on the rheology of homozygous sickle cell disease. Br. J. Haematol. 55:479-486.

39. Steinberg, M. H., W. Rosenstock, M. B. Coleman, J. G. Adams, R. Rieder, O. Platica, M. Cedeno, R. F. Rieder, J. T. Wilson, P. Milner, S. West, and the Cooperative Study of Sickle Cell Disease. 1984. Effects of thalassemia and microcytosis on the hematological and vasoocclusive severity of sickle cell anemia. Blood. 63:1353-1360. 